\title{
Clinical outcomes of extracorporeal membrane oxygenation in acute traumatic lung injury: a retrospective study
}

Hong Kyu Lee ${ }^{1}$, Hyoung Soo Kim"D, Sang Ook Ha², Sunghoon Park ${ }^{3}$, Hee Sung Lee ${ }^{4}$, Soo Kyung Lee ${ }^{5}$ and Sun Hee Lee ${ }^{1}$

\begin{abstract}
Background: Therapeutic extracorporeal membrane oxygenation (ECMO) is a challenging procedure in patients who have experienced severe trauma. Particularly, patients with traumatic lung injury and posttraumatic acute respiratory distress syndrome (ARDS) have a high risk of bleeding during this procedure. This study aimed to determine the safety and feasibility of ECMO in patients with traumatic ARDS.

Methods: We retrospectively reviewed medical records and investigated the clinical outcomes of ECMO in 42 patients with traumatic ARDS, among whom near-drowning (42.9\%) was the most frequent cause of injury.

Results: Thirty-four of 42 patients (81\%) survived and were discharged after a median hospital stay of 23 days. A multivariate analysis identified a lactate level (odds ratio: 1.493, 95\% confidence interval: $1.060-2.103, P=0.022$ ) and veno-venous $(\mathrm{W}) \mathrm{ECMO}$ (odds ratio: $0.075,95 \%$ confidence interval: $0.006-0.901, P=0.041$ ) as favorable independent predictors of survival in patients with traumatic ARDS who underwent ECMO. The optimal cut off value for pre-ECMO lactate level was $10.5 \mathrm{mmol} / \mathrm{L}$ (area under the curve $=0.929, P=0.001$ ). In Kaplan-Meier analysis, the survival rate at hospital discharge was significant higher among the patients with a pre-ECMO lactate level of $10.5 \mathrm{mmol} / \mathrm{L}$ or less compared with patients with pre-ECMO lactate level greater than $10.5 \mathrm{mmol} / \mathrm{L}(93.8 \%$ versus $40.0 \%$, respectively; $P=0.01$ ).

Conclusions: $E C M O$ yielded excellent survival outcomes, particularly in patients with low pre-treatment lactate levels who received W ECMO. Therefore, ECMO appears safe and highly feasible in a carefully selected population of trauma patients.
\end{abstract}

Keywords: Acute respiratory distress syndrome, Extracorporeal membrane oxygenation, Trauma, Traumatic lung injury

\footnotetext{
* Correspondence: cskhs99@hallym.or.kr

'Department of Thoracic and Cardiovascular Surgery, Hallym University Sacred Heart Hospital, Hallym University Medical Center, Gwanpyeong-ro 170 beon-gil 22, Dongan-gu, Anyang-si, Gyeonggi-do 14068, South Korea

Full list of author information is available at the end of the article
}

(c) The Author(s). 2020 Open Access This article is licensed under a Creative Commons Attribution 4.0 International License, which permits use, sharing, adaptation, distribution and reproduction in any medium or format, as long as you give appropriate credit to the original author(s) and the source, provide a link to the Creative Commons licence, and indicate if changes were made. The images or other third party material in this article are included in the article's Creative Commons licence, unless indicated otherwise in a credit line to the material. If material is not included in the article's Creative Commons licence and your intended use is not permitted by statutory regulation or exceeds the permitted use, you will need to obtain permission directly from the copyright holder. To view a copy of this licence, visit http://creativecommons.org/licenses/by/4.0/ The Creative Commons Public Domain Dedication waiver (http://creativecommons.org/publicdomain/zero/1.0/) applies to the data made available in this article, unless otherwise stated in a credit line to the data. 


\section{Background}

Pneumonia, sepsis and trauma are among the most common causes of acute lung injury or acute respiratory distress syndrome (ARDS) [1]. Severe trauma is generally accompanied by various injuries, including traumatic lung injury, leading to posttraumatic ARDS in some patients [2]. Major trauma-induced lung injury is associated with mortality rates as high as $50-80 \%$ due to direct consequences of the injury or secondary effects, such as hypoxemia and respiratory acidosis, including the injured brain [3]. Previous reports have described the efficacy of ECMO support in adult trauma patients with ARDS [4] and trauma patients with severe lung injury [5]. Traditionally, trauma patients have a high risk of bleeding and thus have not been considered suitable candidates for ECMO due to the limited experience of the attending medical practitioners. Accordingly, the utility of ECMO in trauma patients remains unclear.

In this retrospective study, we aimed to evaluate our experiences with ECMO support in patients with lifethreatening acute traumatic lung injury and their clinical outcomes, and to identify the significant factors associated with survival outcomes.

\section{Methods}

We retrospectively reviewed the data from 42 consecutive patients who received ECMO respiratory support for severe trauma-induced acute respiratory failure between January 2007 and December 2018. Since the hospital serves as a regional emergency medical center, all major trauma patients were admitted to the emergency department by Emergency Medical Service. Of the total 42, 10 received ECMO during intensive care in intensive care units (ICUs), while 32 received ECMO at emergency centers before ICU admission. The indications for veno-venous (VV) ECMO were partial arterial oxygen pressure to fractional inspired oxygen concentration $(\mathrm{PaO} 2 / \mathrm{FiO} 2)$ ratio $<100$ with $\mathrm{FiO} 2$ of 1.0 and severe hypercapnia $(\mathrm{pH}<7.25)$ with unstable hemodynamics, despite appropriate conventional ARDS treatment [6]. Venoarterial (VA) or venoarteriovenous (V-AV) ECMO was applied to patients whose ejection fractions on $2 \mathrm{D}$ echocardiograms were $<20 \%$ (Fig. 1). Indications for VA ECMO included coexistent shock (i.e., systolic blood pressure $<80 \mathrm{mmHg}$ ) with hypoxemia or hypercapnia despite fluid resuscitation and vasopressor support. Patients predicted to require high-dose vasopressors (i.e., norepinephrine $>0.5 \mu \mathrm{g} / \mathrm{kg} / \mathrm{min}$ ) during VV ECMO also received V-AV ECMO (Fig. 1). In V-AV ECMO, we inserted the additional arterial cannulae into the femoral artery and connected venous perfusion cannulae in right atrium using Y-connector. We controlled the degree of clamping of the femoral artery cannulae while monitoring the flowmeter for determining the amount of oxygenated perfusion flow and the systemic circulatory support. ECMO was contraindicated for patients with

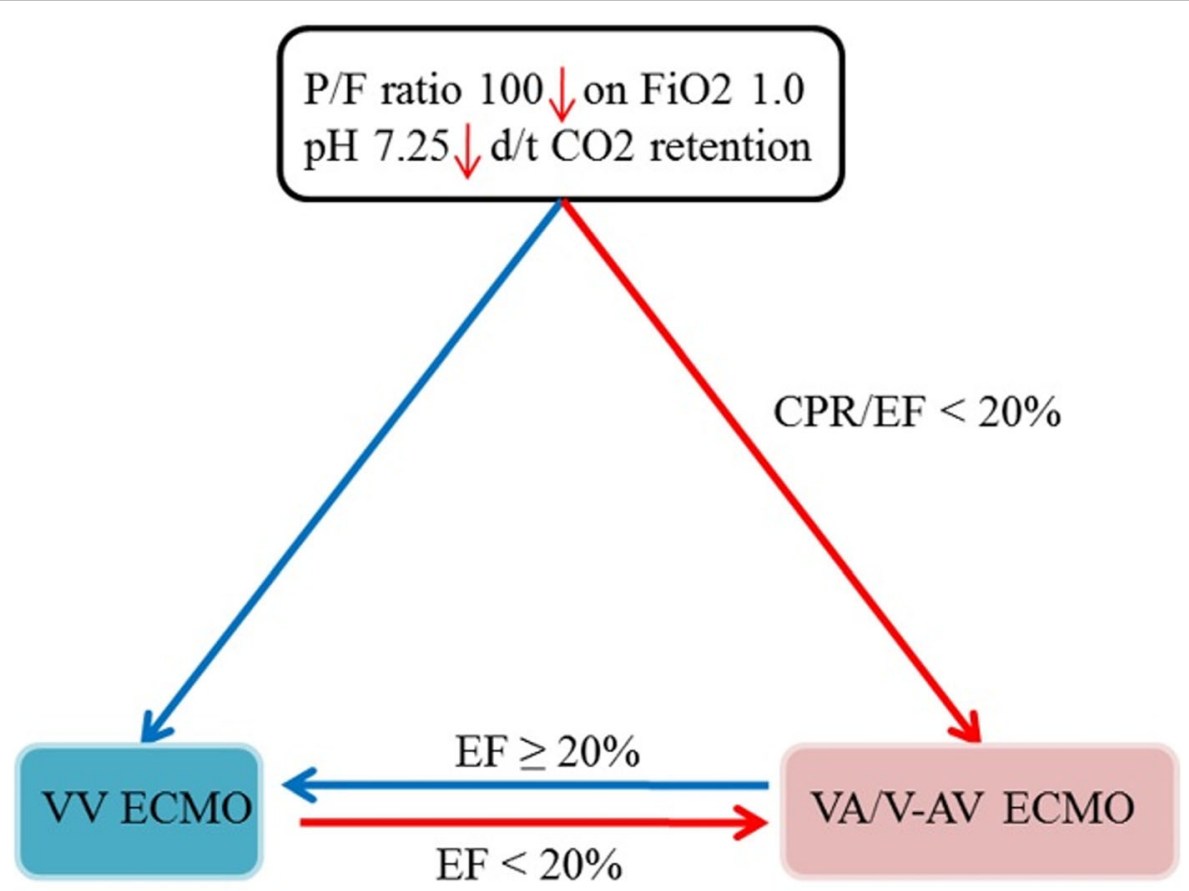

Fig. 1 Schematic of the principle of ECMO configurations. Abbreviations: ECMO, extracorporeal membrane oxygenation; P/F, partial arterial oxygen pressure to fractional inspired oxygen concentration; CPR, cardiopulmonary resuscitation; EF, ejection fraction; W, venovenous; VA. venoarterial; $\mathrm{V}$-AV, venoarteriovenous 
uncontrolled traumatic bleeding, severe hypoxemic brain injury, untreatable cancer and severe disability. Study approval was received from Hallym University Sacred Heart Hospital Institutional Review Board (IRB No. 2019-05-029-001), which waived the requirement for informed consent due to the retrospective design of the study.

\section{ECMO technique and management}

We used two types of centrifugal pumps for ECMO. Until May 2010, the Capiox Emergency Bypass System ${ }^{\circ}$ (Terumo, Inc., Tokyo, Japan) was used at our institution. However, since June 2010, the Centrifugal Rotaflow Pump (Maquet Inc., Hirrlingen, Germany) has been used for most patients [6]. VV ECMO or VA ECMO were cannulated percutaneously using the Seldinger technique under fluoroscopic guidance in a cardiac catheterization laboratory or hybrid operating room in the emergency department. Arterial cannulae (17-21 Fr) and venous cannulae (17-28 Fr; DLP and Bio-Medicus, Medtronic, Minneapolis, MN, USA; RMI, Edward's Lifesciences LLC, Irvine, CA, USA) were used depending on the patient's size. The initial gas and blood flow rates were $4-6$ and $3-5 \mathrm{~L} / \mathrm{min}$, respectively, to maintain an oxygen saturation $(\mathrm{SaO} 2)>90 \%$. During ECMO support, heparin or nafamostat mesilate (SK Chemicals Life Science Biz., Seoul, Korea; licensed by Torii Pharmaceutical, Tokyo, Japan) was used for anticoagulation, with a target activated partial thromboplastin time (aPTT) of 60-80s [7]. Anticoagulation was usually initiated after confirmed bleeding control was achieved for $48 \mathrm{~h}$ in patients with a high risk of bleeding or those who underwent surgery. The following mechanical ventilator settings were applied initially: tidal volume, 4-6 mL/kg; PEEP, 4-8 cm H2O; respiration rate, $10 / \mathrm{min}$ and $\mathrm{FiO} 2,0.21-0.6$. Blood transfusions were administered as packed red blood cells (RBCs) with hemoglobin concentration $<8-10 \mathrm{~g} / \mathrm{dL}$, fresh frozen plasma (FFP) with an international normalized ratio $(\mathrm{INR})>2.0$, platelet concentrate with a count of $<50,000 / \mu \mathrm{L}$, or cryoprecipitate with a fibrinogen concentration of $<150 \mathrm{mg} / \mathrm{dl}$.

ECMO weaning was considered when hemodynamic stability and pulmonary improvement were evident, and implemented once cardiac pulsatility and contractility had improved (left ventricular ejection fraction $\geq 30$ $40 \%$ ). The pump flow and sweep gas were initially tapered to 2 and $0 \mathrm{~L} / \mathrm{min}$, respectively. For VA ECMO weaning, the pump flow was decreased by $1 \mathrm{~L} / \mathrm{min}$ for $24 \mathrm{~h}$. Decannulation was performed after the patient remained stable for $24 \mathrm{~h}$. Weaning was considered successful when the patient remained stable for $48 \mathrm{~h}$ after ECMO removal.

\section{Data collection and statistical analysis}

For each patient, we recorded demographics (age, sex, and body mass index), comorbidities, causes of injury, the Inotropic Score (IS), the Vasoactive-Inotropic Score (VIS), illness severity measure scores [Simplified Acute Physiology Score II (SAPSII) and Sequential Organ Failure Assessment (SOFA)] and laboratory data obtained immediately before initiating ECMO support. The IS have been used in clinical research as measures of illness severity in patients undergoing congenital heart surgery [8]. Several studies showed that the VIS, which indicates the amount of cardiovascular support by various inotropes or vasopressors, was independently predictive of clinical outcomes in patients who underwent cardiac surgery and in sepsis patiets [9]. The SAPS II and SOFA are severity scores and mortality estimation tools that were developed for patients in medical or surgical ICUs [10]. We also recorded the ECMO durations and weaning rates, transfusion and complication rates and all outcomes. All data obtained during ECMO support were compared between survivors and non-survivors. All results are presented as numbers with percentages for categorical variables, and as medians with interquartile ranges (IQRs) for continuous variables. The MannWhitney $U$ test or repeated-measure analysis of variance (ANOVA) was used to compare continuous variables, whereas the chi-squared or Fisher's exact test was used to compare categorical variables.

Univariate and multivariate logistic regression analyses were performed to identify independent risk factors for hospital mortality among the pre-ECMO variables and treatment variables during ECMO. Covariates identified as significant $(P<0.05)$ in the univariate analysis were included in the multivariate analysis. We further conducted a receiver operating characteristic curve analysis to identify the relevant cut-off values of independent pre-ECMO variables. Groups stratified using a preECMO lactate concentration cut-off of $10.5 \mathrm{mmol} / \mathrm{L}$ were then subjected to a survival analysis based on the Kaplan-Meier method. IBM SPSS version 24.0 software for Windows (IBM Corp., Armonk, NY, USA) was used for all statistical analyses.

\section{Results}

\section{Baseline characteristics}

The baseline characteristics of the 42 patients who underwent ECMO following an acute traumatic lung injury are shown in Table 1. Thirty-seven $(88.1 \%)$ of these patients were male, and the median age was 41 years. Acute traumatic lung injury was most frequently attributed to near drowning $(n=18,42.9 \%)$, traffic accidents $(n=9,21.4 \%)$, crush injuries to the chest $(n=5,11.9 \%)$, falls from significant heights $(n=4,9.5 \%)$, pulmonary hemorrhage due to stabbing $(n=2,4.8 \%)$ or gunshot 
Table 1 Comparison of baseline characteristics in survivors and non-survivors

\begin{tabular}{|c|c|c|c|c|}
\hline Pre-ECMO & Total & Survivors & Non-survivors & $P$ \\
\hline Variables & $n=42(\%)$ & $n=34(81 \%)$ & $n=8(19 \%)$ & \\
\hline Sex & & & & 0.564 \\
\hline Male & $37(88.1)$ & $29(69)$ & $8(19)$ & \\
\hline Female & $5(11.9)$ & $5(11.9)$ & $0(0)$ & \\
\hline Age (years), median (IQR) & $41(18.75-52.75)$ & $39(18.75-48.0)$ & $49.5(24.5-59.0)$ & 0.378 \\
\hline BMI $\left(\mathrm{kg} / \mathrm{m}^{2}\right)$, median (IQR) & $22.3(20.7-24.0)$ & $22.5(21.1-24.5)$ & 21.1(16.7-21.9) & 0.277 \\
\hline \multicolumn{5}{|l|}{ Comorbidity } \\
\hline Diabetes & $5(11.9)$ & $5(11.9)$ & $0(0)$ & 0.327 \\
\hline Hypertension & $6(14.3)$ & $5(11.9)$ & $1(2.4)$ & 0.681 \\
\hline Liver cirrhosis & $2(4.8)$ & $0(0)$ & $2(4.8)$ & $0.033^{*}$ \\
\hline Asthma & $1(2.4)$ & $0(0)$ & $1(2.4)$ & 0.190 \\
\hline CPR & $21(50)$ & $16(38.1)$ & $5(11.9)$ & 0.348 \\
\hline MV before ECMO, median days (IQR) & $1(1-2.25)$ & $1(1-1.25)$ & $1(1-5.25)$ & 0.270 \\
\hline Door to ECMO, median hours (IQR) & $3.5(2-81)$ & $3.5(2.2-81)$ & e & 0.328 \\
\hline ECMO within $24 \mathrm{~h}$ & $28(67)$ & $23(58)$ & $5(11.9)$ & 0.543 \\
\hline Surgical procedures & $17(40.5)$ & $13(31)$ & $4(9.5)$ & 0.411 \\
\hline e Surgical procedures with ECMO & $6(14.3)$ & $6(14.3)$ & $0(0)$ & \\
\hline Thoracic/abdominal/neuro/skeletal & $4 / 0 / 0 / 2$ & $4 / 0 / 0 / 2$ & $0 / 0 / 0 / 0$ & \\
\hline ECMO after surgical procedures & $11(26.2)$ & $7(16.7)$ & $4(9.5)$ & \\
\hline Thoracic/abdominal/neuro/skeletal & $3 / 4 / 1 / 3$ & $3 / 1 / 1 / 2$ & $0 / 3 / 0 / 1$ & \\
\hline IS, mean (range) & $4.28(0-44.44)$ & $4.64(0-44.44)$ & $2.75(0-22.0)$ & 0.680 \\
\hline VIS, mean (range) & $61.09(0-446.0)$ & $35.68(0-285.0)$ & $169.09(0-446.0)$ & $0.001^{*}$ \\
\hline SOFA score, mean (range) & $11.50(4.0-19.0)$ & $11.23(4.0-16.0)$ & $12.62(8.0-19.0)$ & 0.289 \\
\hline SAPSII score, mean (range) & $54.57(26.0-86.0)$ & $51.08(26.0-84.0)$ & $69.37(42.0-86.0)$ & $0.010^{*}$ \\
\hline Trauma types & & & & 0.569 \\
\hline Car accident & $9(21.4)$ & $8(19)$ & $1(2.4)$ & \\
\hline Near drowning & $18(42.9)$ & $15(35.7)$ & $3(7.1)$ & \\
\hline Gunshot wound & $1(2.4)$ & $1(2.4)$ & $0(0)$ & \\
\hline Intoxication & $2(4.8)$ & $1(2.4)$ & $1(2.4)$ & \\
\hline Crushing injury & $5(11.9)$ & $3(7.1)$ & $2(4.8)$ & \\
\hline Fall down & $4(9.5)$ & $4(9.5)$ & $0(0)$ & \\
\hline Hanging & $1(2.4)$ & $1(2.4)$ & $0(0)$ & \\
\hline Stabbed wound & $2(4.8)$ & $1(2.4)$ & $1(2.4)$ & \\
\hline Associated injury & & & & $0.042^{*}$ \\
\hline Thorax & $20(47.6)$ & $17(40.5)$ & $3(7.1)$ & \\
\hline$T+$ head & $5(11.9)$ & $4(9.5)$ & $1(2.4)$ & \\
\hline T+abdomen & $1(2.4)$ & $0(0)$ & $1(2.4)$ & \\
\hline $\mathrm{T}+\mathrm{H}+\mathrm{A}+$ pelvis & $1(2.4)$ & $1(2.4)$ & $0(0)$ & \\
\hline $\mathrm{T}+\mathrm{H}+\mathrm{A}+\mathrm{P}+\mathrm{MSI}$ & $2(4.8)$ & $2(4.8)$ & $0(0)$ & \\
\hline $\mathrm{T}+\mathrm{H}+\mathrm{A}+\mathrm{MSI}$ & $3(7.1)$ & $3(7.1)$ & $0(0)$ & \\
\hline $\mathrm{T}+\mathrm{H}+\mathrm{MSI}$ & $1(2.4)$ & $1(2.4)$ & $0(0)$ & \\
\hline$T+A+P+M S I$ & $1(2.4)$ & $1(2.4)$ & $0(0)$ & \\
\hline$T+A+P$ & $1(2.4)$ & $0(0)$ & $1(2.4)$ & \\
\hline$T+P+M S I$ & $1(2.4)$ & $0(0)$ & $1(2.4)$ & \\
\hline
\end{tabular}


Table 1 Comparison of baseline characteristics in survivors and non-survivors (Continued)

\begin{tabular}{llll}
\hline Pre-ECMO & Total & Survivors & Non-survivors \\
Variables & $n=42(\%)$ & $n=34(81 \%)$ & $n=8(19 \%)$ \\
\hline T+MSI & $5(11.9)$ & $5(11.9)$ & $0(0)$ \\
A & $1(2.4)$ & $0(0)$ & $1(2.4)$ \\
ECMO equipment & & & $1(2.4)$ \\
EBS & $6(14.3)$ & $5(11.9)$ & $7(16.7)$ \\
PLS & $36(85.7)$ & $29(69)$ & 0.873 \\
\hline
\end{tabular}

Abbreviations: $A$ abdomen, $B M I$ body mass index, $C P R$ cardiopulmonary resuscitation, $E C M O$ extracorporeal membrane oxygenation, $H$ head, $I Q R$ interquartile range, IS inotropic score dopamine $(\mathrm{mcg} / \mathrm{kg} / \mathrm{min})+$ dobutamine $(\mathrm{mcg} / \mathrm{kg} / \mathrm{min})+100 \mathrm{x}$ epinephrine $(\mathrm{mcg} / \mathrm{kg} / \mathrm{min})+100, M S I \mathrm{musculoskeletal}$ injury, MV mechanical ventilation, $P$ pelvis, SAPSII Simplified Acute Physiology Score II, SOFA Sequential Organ Failure Assessment, $T$ thorax, VIS Vasoactive-Inotropic Score IS + $100 \mathrm{x}$ norepinephrine $(\mathrm{mcg} / \mathrm{kg} / \mathrm{min})+10 \times$ milrinone $(\mathrm{mcg} / \mathrm{kg} / \mathrm{min})+10,000 \times$ vasopressin $(U \mathrm{nits} / \mathrm{kg} / \mathrm{min})$

*Statistically significant, $P<0.05$

wounds to the chest $(\mathrm{n}=1,2.4 \%)$, intoxication-induced pneumonitis $(n=2,4.8 \%)$ and hanging $(n=1,2.4 \%)$. Most of the associated injuries occurred in the thorax. Seventeen (40.5\%) patients required surgical treatment, of whom 7 (16.6\%), 5 (11.9\%), 4 (9.5\%) and 1 (2.4\%) underwent thoracic, skeletal, abdominal, or neurosurgery, respectively. Before ECMO, the mean IS, VIS, SOFA score and SAPSII were 4.28, 61.09, 11.50 and 54.57, respectively. The pre-ECMO median $\mathrm{pH}, \mathrm{PaO} 2$, PCO2 and $\mathrm{PaO} 2 / \mathrm{FiO} 2$ were $7.19,60.5 \mathrm{mmHg}, 47.0$ $\mathrm{mmHg}$ and 61.5, respectively (Table 2).

Patients received the following types of ECMO: VV ECMO, 29 (69\%); VA, 7 (16.7\%), among whom 1 (2.4\%) subsequently received VV; VV followed by VAV, 2 (4.8\%); VAV followed by VV, 1 (2.4\%) and VAV, 3 (7.1\%). The median time of door to ECMO was all $3.5 \mathrm{~h}$ for total, survivors, and non-survivors group $(p=0.328)$. The number of patients who received ECMO within 24 h was 28, 23, and 5 for total, survivors, and nonsurvivors group $(p=0.543)$. The median ICU stay was 16 days. Thirty-four of 42 patients (81\%) survived and were discharged after a median hospital stay of 23 days (Table 3). Patients receiving VV ECMO had better survival rates than those receiving other types of ECMO.

\section{Comparisons between survivors and non-survivors}

Next, we compared the characteristics of survivors and non-survivors to identify risk factors for mortality. Notably, survivors had a lower VIS and SAPSII (Table 1) and higher platelet count and arterial blood $\mathrm{pH}$, while non-survivors had higher prolonged aPTT, INR and lactate concentration values (Table 2). Survivors also required significantly fewer transfusions (Table 3). The following complications occurred during ECMO: acute renal failure (creatinine $>2 \mathrm{mg} / \mathrm{dL}$ ) in 11 (26.2\%) patients, bed sores in $2(4.8 \%)$, cholecystitis in $2(4.8 \%)$,

Table 2 Comparisons of laboratory findings between survivors and non-survivors

\begin{tabular}{|c|c|c|c|c|}
\hline Pre-ECMO & Total & Survivors & Non-survivors & $P$ \\
\hline Variables, median & $n=42(\mathrm{IQR})$ & $n=34(\mathrm{IQR})$ & $n=8(\mathrm{IQR})$ & \\
\hline Hemoglobin (g/dL) & $12.8(10.6-15.3)$ & $13.2(10.8-15.6)$ & $11.5(8.0-12.6)$ & 0.098 \\
\hline Platelet count (cells/ $\mu \mathrm{L}$ ) & 199.5 (100.5-276.2) & $237(132.0-287.2)$ & $79(43.5-167.5)$ & $0.003^{*}$ \\
\hline Activated PTT (s) & $43.3(31.5-64.1)$ & $39.8(30.8-50.0)$ & $91.7(62.6-107.4)$ & $0.003^{*}$ \\
\hline INR & $1.2(1.1-1.4)$ & $1.1(1.0-1.3)$ & $1.7(1.7-2.5)$ & $0.002^{*}$ \\
\hline \multicolumn{5}{|l|}{$A B G A$} \\
\hline $\mathrm{pH}$ & $7.19(7.01-7.31)$ & $7.24(7.0-7.3)$ & $6.95(6.83-7.06)$ & $0.002^{*}$ \\
\hline $\mathrm{PaO}_{2} \mathrm{mmHg}$ & $60.5(51.1-77.2)$ & $60.5(51.1-74.4)$ & $58.7(39.5-88.1)$ & 0.144 \\
\hline $\mathrm{PaCO}_{2} \mathrm{mmHg}$ & $47.0(38.9-62.4)$ & $46.1(38.5-59.0)$ & $60(50.3-109.7)$ & 0.409 \\
\hline $\mathrm{PaO}_{2} / \mathrm{FiO}_{2}$ & $61.5(49.7-81.7)$ & $63(51.1-80.7)$ & $55.9(35.0-83.8)$ & 0.686 \\
\hline $\mathrm{BUN}(\mathrm{mg} / \mathrm{dL})$ & $15.7(12.0-21.1)$ & $15.7(11.0-19.9)$ & $16.8(13.7-23.3)$ & 0.519 \\
\hline Creatinine (mg/dL) & $1.1(0.8-1.3)$ & $1.0(0.8-1.3)$ & $1.3(0.8-1.9)$ & 0.125 \\
\hline Bilirubin (mg/dL) & $0.8(0.4-1.6)$ & $0.8(0.4-1.6)$ & $0.6(0.2-1.8)$ & 0.647 \\
\hline Lactate (mmol/L) & $6.7(2.6-11.5)$ & $5.7(2.4-9.2)$ & $15.0(12.5-18.4)$ & $0.001^{*}$ \\
\hline
\end{tabular}

Abbreviations: $A B G A$ arterial blood gas analysis, BUN blood urea nitrogen, ECMO extracorporeal membrane oxygenation, INR international normalized ratio, IQR interquartile range, $\mathrm{PaCO} 2$ partial arterial carbon dioxide pressure, $\mathrm{PaO} 2$ partial arterial oxygen saturation, $P T T$ partial thromboplastin time * Statistically significant, $P<0.05$ 
Table 3 Comparison of treatments and outcomes between survivors and non-survivors

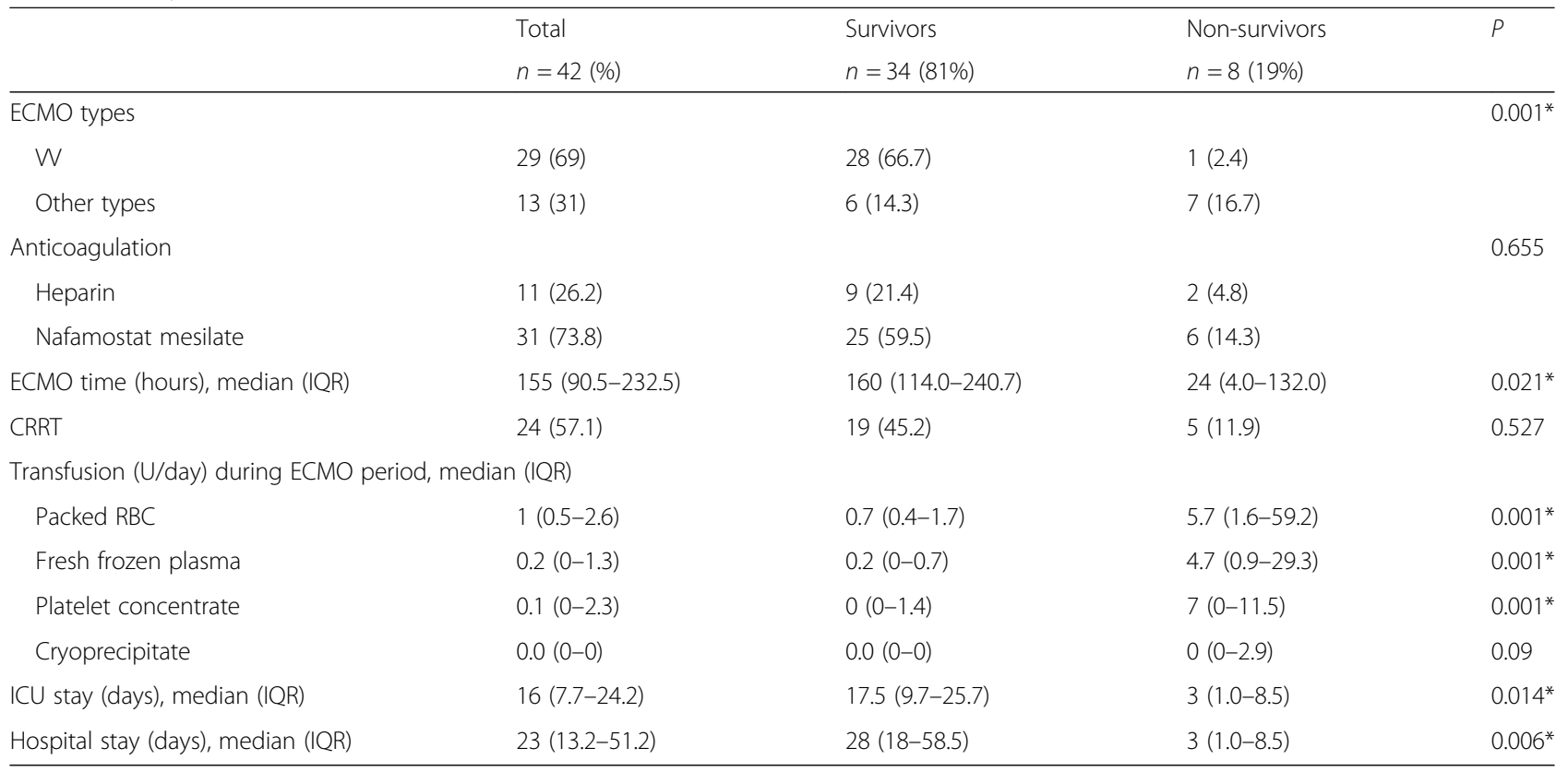

Abbreviations: $C R R T$ continuous renal replacement therapy, ECMO extracorporeal membrane oxygenation, ICU intensive care unit, $I Q R$ interquartile range, $R B C$ red blood cells, $W$ veno-venous

*Statistically significant, $P<0.05$

multi-organ failure in $2(4.8 \%)$, central nervous system injury (hemorrhage) in 1 (2.4\%), ulcer bleeding in 1 (2.4\%), and leg ischemia in $1(2.4 \%)$ patient (Table 4$)$.

The investigated pre-ECMO variables were defined by considering the overlapping meaning between the variables. Ultimately, we included six variables identified as significant in the univariate analysis-SAPSII, aPTT, INR, $\mathrm{pH}$, platelet count and lactate level-in a subsequent multivariate analysis (Table 5). We identified the lactate level as an independent predictor of survival [odds ratio (OR), 1.493; 95\% confidence interval (CI), $1.060-2.103, P=0.022]$, with an area under the receiver operating characteristic curve of 0.929 (95\% CI, $0.840-$ $1.000, P=0.001$; Fig. 2) and estimated cut-off value of $10.5 \mathrm{mmol} / \mathrm{L}$ (sensitivity: 0.857 , specificity: 0.867 ). This cut-off yielded a significant difference in survival in a
Kaplan-Meier analysis $(P=0.01$, Fig. 3). Finally, univariate and multivariate analyses of four treatment variables revealed a favorable association of VV ECMO (OR: 0.075, 95\% CI: $0.006-0.901, P=0.041)$ with survival (Table 6).

\section{Discussion}

Trauma patients with severe injuries are at risk of ARDS via direct and indirect causes, including lung contusions, aspiration pneumonia, massive blood transfusion and fat embolism syndrome [11]. ARDS remains a common post-traumatic complication and is diagnosed in $6.5 \%$ of patients requiring mechanical ventilation for $>48 \mathrm{~h}$ [12]. If optimal ventilator strategies and adjunctive measures fail to yield improvement, ECMO might be considered to provide temporary respiratory or cardiac support in

Table 4 Comparison of complications during ECMO between survivors and non-survivors

\begin{tabular}{|c|c|c|c|c|}
\hline & $\begin{array}{l}\text { Total } \\
n=42(\%)\end{array}$ & $\begin{array}{l}\text { Survivors } \\
n=34 \text { (81\%) }\end{array}$ & $\begin{array}{l}\text { Non-survivors } \\
n=8(19 \%)\end{array}$ & P \\
\hline Leg ischemia & $1(2.4)$ & $0(0)$ & $1(2.4)$ & 0.190 \\
\hline Bed sore & $2(4.8)$ & $2(4.8)$ & $0(0)$ & 0.652 \\
\hline ARF (creatinine $>2 \mathrm{mg} / \mathrm{dL}$ ) & $11(26.2)$ & $5(11.9)$ & $6(14.3)$ & $0.002^{*}$ \\
\hline Cholecystitis & $2(4.8)$ & $2(4.8)$ & $0(0)$ & 0.652 \\
\hline Ulcer bleeding & $1(2.4)$ & $1(2.4)$ & $0(0)$ & 0.810 \\
\hline CNS injury & $1(2.4)$ & $0(0)$ & $1(2.4)$ & 0.190 \\
\hline Multiorgan failure & $2(4.8)$ & $1(2.4)$ & $1(2.4)$ & 0.348 \\
\hline
\end{tabular}

Abbreviations: ARF acute renal failure, CNS central nervous system, ECMO extracorporeal membrane oxygenation *Statistically significant, $P<0.05$ 
Table 5 Associations of pre-ECMO variables with survival in univariate and multivariate analyses

\begin{tabular}{|c|c|c|c|c|c|c|}
\hline & \multicolumn{2}{|l|}{ Univariate } & \multirow[t]{2}{*}{$P$} & \multicolumn{2}{|l|}{ Multivariate } & \multirow[t]{2}{*}{$P$} \\
\hline & Odds ratio & $95 \% \mathrm{Cl}$ & & Odds ratio & $95 \% \mathrm{Cl}$ & \\
\hline SAPSII score & 1.068 & $1.010-1.129$ & 0.022 & - & - & - \\
\hline aPTा & 1.031 & $1.006-1.057$ & 0.014 & - & - & - \\
\hline INR & 4.610 & $1.378-15.417$ & 0.013 & - & - & - \\
\hline $\mathrm{pH}$ in $\mathrm{ABGA}$ & 0.001 & $0.000-0.163$ & 0.009 & - & - & - \\
\hline Platelet count & 0.984 & $0.972-0.997$ & 0.013 & 0.978 & $0.956-1.001$ & 0.063 \\
\hline Lactate concentration & 1.536 & $1.131-2.087$ & 0.006 & 1.493 & $1.060-2.103$ & $0.022^{*}$ \\
\hline
\end{tabular}

Abbreviations: $A B G A$ arterial blood gas analysis, $C l$ confidence interval, $E C M O$ extracorporeal membrane oxygenation, INR international normalized ratio, $P T T$ partial thromboplastin time, SAPSII Simplified Acute Physiology Score II, VIS vasoactive inotropic score

*Statistically significant, $P<0.05$

patients with cardiopulmonary failure and to allow the lungs to rest through manipulation the ventilator settings and the concentration of inspired oxygen while maintaining appropriate oxygenation, carbon dioxide removal, and tissue perfusion [13]. However, this potentially life-saving intervention is not without complications. Bleeding and thrombotic complications are the major causes of ECMO-associated morbidity and mortality [14]. The use of anticoagulant therapy is recommended to prevent thrombosis during ECMO support, however, the risk of thromboembolic complications must be balanced with the risk of bleeding. Accordingly, the use of ECMO in trauma patients is limited by the high risk of hemorrhage during and after cannulation, particularly in the presence of severe coagulopathy, contraindications to anticoagulant treatment and the risk of intracranial hemorrhage following traumatic brain injury. However, technological advances have significantly improved the characterizations of bleeding profiles. Arlt et al. [15] reported that the delayed use of heparin in 10

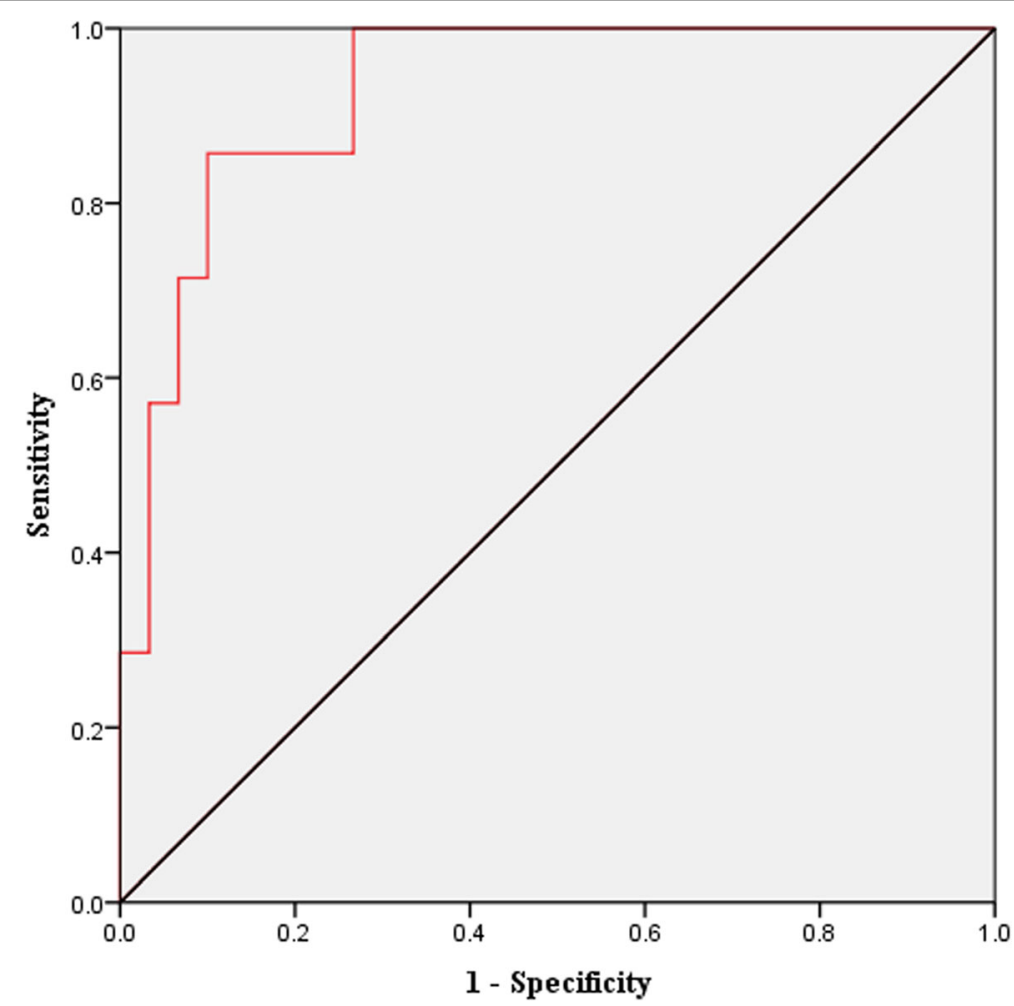

Fig. 2 Receiver operating characteristic curve for predictability of pre-ECMO lactate level for survival to hospital discharge. The area under the receiver operating characteristic curve was 0.929 (95\% confidence interval: 0.840 to 1.000, $P=0.001$ ) for pre-ECMO lactate level. The optimal cut off value of pre-ECMO lactate level was $10.5 \mathrm{mmol} / \mathrm{L}$ for predicting survival at hospital discharge. In analysis of pre-ECMO lactate level $10.5 \mathrm{mmol} /$ $L$, sensitivity of $85.7 \%$, specificity of $86.7 \%$, positive predictive value of $93.8 \%$, and negative predictive value of $60.0 \%$ were noted. Abbreviation: ECMO, extracorporeal membrane oxygenation. 


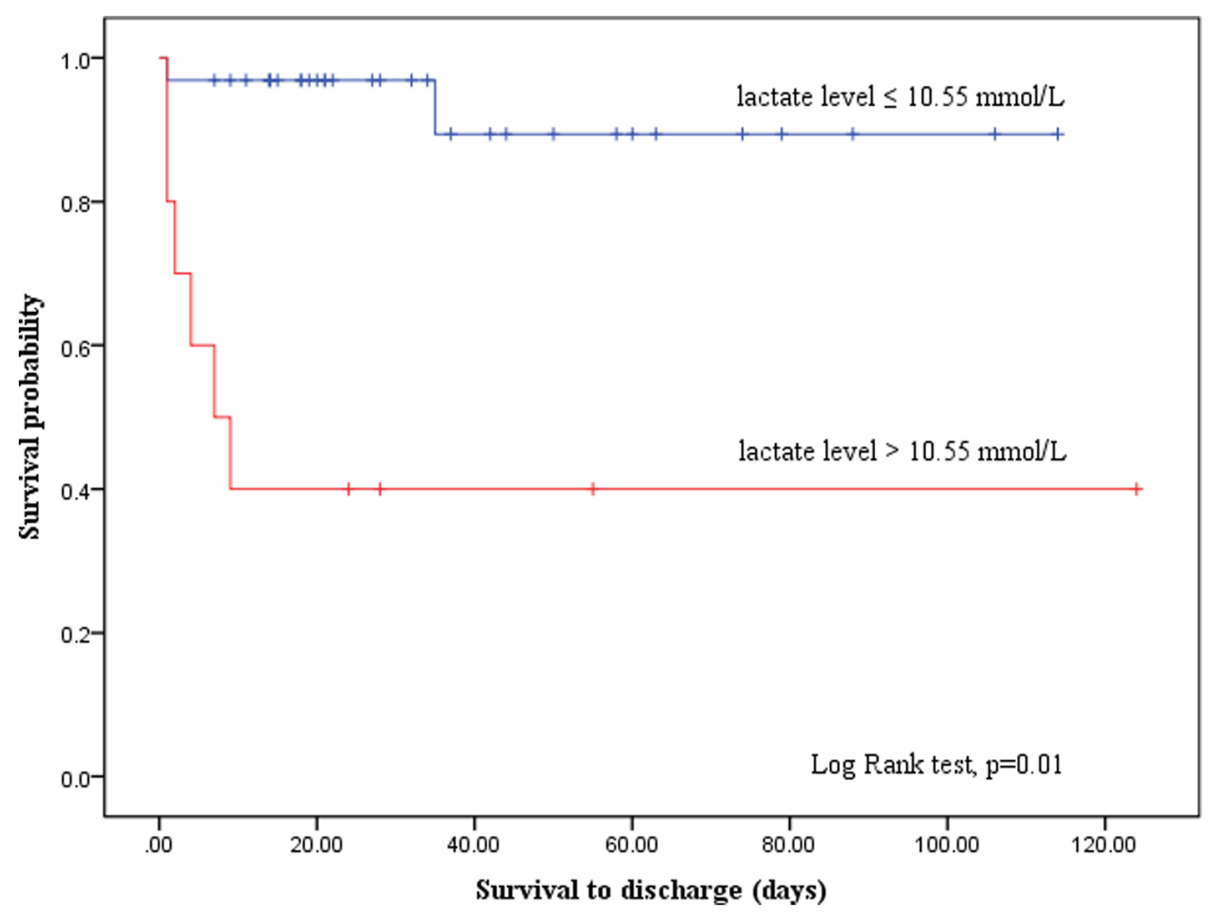

Fig. 3 Kaplan-Meier survival analysis based on lactate concentration. Kaplan-Meier survival curve for survival to hospital discharge between patients with pre-ECMO lactate level above $10.5 \mathrm{mmol} / \mathrm{L}$ (red line) and below $10.5 \mathrm{~mol} / \mathrm{L}$ (blue line). The cumulative survival rate at hospital discharge was significantly higher for patients with a pre-ECMO lactate level of $10.5 \mathrm{mmol} / \mathrm{L}$ or less(blue line) compared with patients having a pre-ECMO lactate level greater than $10.5 \mathrm{mmol} / \mathrm{L}$ (red line, $93.8 \%$ versus $40.0 \%$, respectively; $P=0.01$ )

trauma patients did not lead to any adverse thrombotic events. Moreover, a case series described 3 cases involving delayed heparin administration due to traumatic hemorrhage and/or brain injury [16], with times to heparinization after cannulation ranging from $24 \mathrm{~h}$ to 5 days. All the patients survived to discharge, and only 1 experienced a thrombotic complication (IVC clots) that was resolved by heparinization after decannulation.

We administered nafamostat mesilate during ECMO support to patients with acute renal failure or at a high risk of bleeding. This synthetic serine protease inhibitor has a very short half-life and inhibits coagulation by inactivating thrombin, the activated coagulation factors XIIa and Xa, complement factors $\mathrm{C} 1 \mathrm{r}$ and $\mathrm{C} 1 \mathrm{~s}$, plasmin, trypsin and kallikrein 10,11, 12, 13 and 14 . We previously used nafamostat instead of heparin to reduce bleeding complications in patients receiving ECMO, with acceptable results [7].

Regarding survival, Cordell-Smith et al. [13] reported that 20 of 28 patients (71\%) who received ECMO for severe trauma-related respiratory failure survived, with pre-ECMO ventilation times of 61 and $87 \mathrm{~h}$ for survivors and non-survivors, respectively. Ried et al. [17] evaluated 26 patients who received VV ECMO for severe traumarelated respiratory failure after mean 2.6 days of preECMO ventilation and reported an $81 \%$ survival rate. Another study reported an overall survival rate of $56 \%$ among 176 patients supported with VV ECMO, and the best survival rate among trauma patients with a preECMO ventilation interval of 4 days $(71 \%, 10 / 14$

Table 6 Associations of treatment variables with survival in univariate and multivariate analyses

\begin{tabular}{|c|c|c|c|c|c|c|}
\hline & \multicolumn{2}{|l|}{ Univariate } & \multirow[t]{2}{*}{$P$} & \multicolumn{2}{|l|}{ Multivariate } & \multirow[t]{2}{*}{$P P$} \\
\hline & Odds ratio & $95 \% \mathrm{Cl}$ & & Odds ratio & $95 \% \mathrm{Cl}$ & \\
\hline Packed RBC & 1.993 & $1.113-3.568$ & 0.020 & - & - & - \\
\hline Platelet concentration & 1.388 & $1.090-1.768$ & 0.008 & - & - & - \\
\hline Fresh frozen plasma & 1.983 & $1.076-3.378$ & 0.028 & 1.811 & $0.866-3.788$ & 0.114 \\
\hline ECMO types & 0.031 & $0.003-0.297$ & 0.003 & 0.075 & $0.006-0.901$ & $0.041^{*}$ \\
\hline
\end{tabular}

Abbreviations: $\mathrm{Cl}$ confidence interval, $E C M O$ extracorporeal membrane oxygenation, $R B C$ red blood cells *Statistically significant, $P<0.05$ 
patients) [18]. Similarly, we calculated an overall survival rate of $81 \%(n=34)$ in our cohort of 42 patients, 29 (69\%) of whom were supported with VV ECMO. Both survivors and non-survivors received pre-ECMO ventilation for 1 day. We observed associations of the preECMO VIS and SAPSII with mortality during ECMO support, consistent with our previous observation of the former as an important predictor of mortality in patients receiving ECMO support in emergency departments [6]. Therefore, we suggest that a preexisting severity scoring system may be useful for predicting mortality in trauma patients. However, the SOFA score had limited utility in our study population.

Regarding survival predictors, Enger and colleagues [19] developed a new lactate-based risk score for preECMO mortality and reported significantly higher values in non-survivors than in survivors. In our multivariate analysis, we similarly identified lactate level as a significant predictor of survival, using a cut-off value of 10.5 $\mathrm{mmol} / \mathrm{L}$.

Generally, VV ECMO assists the lungs, VA ECMO assists the heart, and VAV ECMO simultaneously assists the lungs and heart. In the patients with acute respiratory failure due to traumatic lung injury or posttraumatic ARDS, the VV ECMO application is the most common due to hypoxia and accounted for $69 \%(n=29)$ in this present study. In other cases, VA ECMO $(n=7,16.7 \%)$ was applied when the circulatory failure was main problem than hypoxia, and VAV ECMO $(n=6,14.3 \%)$ was applied when both the lungs and the heart was main problem and needed assistance at the same time. It is commonly known that the mortality increases when two organs are involved rather than one. Furthermore, the 2020 Extracorporeal Life Support Organization Registry reported that the rate of survival to discharge in the patients with pulmonary support was higher than those with cardiac support or extracorporeal cardiopulmonary resuscitation (60\% versus 43 and 29\%). Similarly, VV ECMO was also associated with better survival outcomes than other types of ECMO support in the present study. We attribute the reasons of these results to be high severity of injuries and hazard statuses of patients receiving other types of ECMO, who usually require cardiac and pulmonary support. Guirand et al. [20] reported an independent association between VV ECMO support and survival in adult trauma patients, regardless of the transfusion requirement or complications due to the frequency of bleeding. Similarly, VV ECMO was also associated with better survival outcomes vs. other types of ECMO support. We attribute this finding to the severity of injuries and hazard statuses of patients receiving other types of ECMO, who usually require cardiac and pulmonary support.

Our study had some limitations. First, the cohort was small, uncontrolled, unicenter and the retrospective design may have introduced unidentified bias. Furthermore, we did not investigate long-term follow-up data. Although ECMO remains controversial in trauma patients with severe ARDS, its increased use suggests nationwide acceptance and/or increased availability at trauma centers. Our observation that ECMO support is associated with favorable outcomes in patients with traumatic ARDS suggests the validity of this salvage method in this population.

\section{Conclusions}

We observed a good survival rate among patients receiving ECMO following acute respiratory failure due to severe traumatic injury. Lung support ECMO may be a feasible, safe, and favorable alternative to conventional treatment in a carefully selected trauma population.

\section{Abbreviations}

ARDS: Acute respiratory distress syndrome; ECMO: Extracorporeal membrane oxygenation; W-ECMO: Veno-venous extracorporeal membrane oxygenation; PaO2: Partial arterial oxygen pressure; FiO2: Fractional inspired oxygen concentration; VA ECMO: Venoarterial extracorporeal membrane oxygenation; V-AV ECMO: Venoarteriovenous extracorporeal membrane oxygenation; SaO2: Oxygen saturation; aPTT: Activated partial thromboplastin time; CRRT: Continuous renal replacement therapy; RBC: Red blood cells; FFP: Fresh frozen plasma; INR: International normalized ratio; VIS: VasoactiveInotropic Score; SAPSII: Simplified Acute Physiology Score II; SOFA: Sequential Organ Failure Assessment; IQR: Interquartile range; ANOVA: Analysis of variance; Cl: Confidence interval

\section{Acknowledgements \\ Not applicable.}

\section{Consent for publications}

Not applicable.

\section{Authors' contributions}

Study conception: HSK. Design: HKL. Acquisition of data: HSK, SHL, HSL, SHP, $\mathrm{SOH}$. Analysis and interpretation of data: HSK, HKL, SHP. Drafting of the manuscript: HKL, HSK. Critical revision of the manuscript for important intellectual content: HSL, SKL, SOH. All the authors read and approved the final manuscript. None of the authors has any conflict of interest, financial or otherwise.

\section{Availability of data and materials}

The data that support the finings of this study are available from the corresponding author upon reasonable request.

\section{Ethics approval and consent to participate}

Study approval was received from Hallym University Sacred Heart Hospital Institutional Review Board (IRB No. 2019-05-029-001), which waived the requirement for informed consent due to the retrospective design of the study.

\section{Competing interests}

The authors declare that they have no competing interests.

\section{Author details}

${ }^{1}$ Department of Thoracic and Cardiovascular Surgery, Hallym University Sacred Heart Hospital, Hallym University Medical Center, Gwanpyeong-ro 170 beon-gil 22, Dongan-gu, Anyang-si, Gyeonggi-do 14068, South Korea. ${ }^{2}$ Department of Emergency Medicine, Hallym University Sacred Heart Hospital, Hallym University Medical Center, Anyang-si, Gyeonggi-do, South Korea. ${ }^{3}$ Division of Pulmonary, Allergy, and Critical Care Medicine, Hallym University Sacred Heart Hospital, Hallym University Medical Center, Anyang-si, Gyeonggi-do, South Korea. ${ }^{4}$ Department of Thoracic and Cardiovascular 
Surgery, Hallym University Dongtan Sacred Heart Hospital, Hallym University Medical Center, Hwaseong-si, Gyeonggi-do, South Korea. ${ }^{5}$ Department of Anesthesiology and Pain Medicine, Hallym University Sacred Heart Hospital, Hallym University Medical Center, Anyang-si, Gyeonggi-do, South Korea.

Received: 2 March 2020 Accepted: 29 April 2020

Published online: 24 May 2020

\section{References}

1. Ware $L B$, Matthay MA. The acute respiratory distress syndrome. N Engl J Med. 2000;342:1334-49.

2. Acute Respiratory Distress Syndrome Network, Brower RG, Matthay MA, Morris A, Schoenfeld D, Thompson BT, et al. Ventilation with lower tidal volumes as compared with traditional tidal volumes for acute lung injury and the acute respiratory distress syndrome. N Engl J Med. 2000;342:1301-8.

3. Watkins TR, Nathens AB, Cooke CR, Psaty BM, Maier RV, Cuschieri J, et al. Acute respiratory distress syndrome after trauma: development and validation of a predictive model. Crit Care Med. 2012;40:2295-303.

4. Wu SC, Chen WT, Lin HH, Fu CY, Wang YC, Lo HC, et al. Use of extracorporeal membrane oxygenation in severe traumatic lung injury with respiratory failure. Am J Emerg Med. 2015;33:658-62.

5. Madershahian N, Wittwer T, Strauch J, Franke UF, Wippermann J, Kaluza M, et al. Application of ECMO in multitrauma patients with ARDS as rescue therapy. J Card Surg. 2007;22:180-4.

6. Kim KI, Lee HS, Kim HS, Ha SO, Lee WY, Park SJ, et al. The pre-ECMO simplified acute physiology score II as a predictor for mortality in patients with initiation ECMO support at the emergency department for acute circulatory and/or respiratory failure: a retrospective study. Scand J Trauma Resusc Emerg Med. 2015;23:59.

7. Han SJ, Han W, Song HJ, Whang SM, Hong KS, Lee WK, et al. Use of nafamostat mesilate as an anticoagulant during extracorporeal membrane oxygenation. J Korean Med Sci. 2011;26:945-50.

8. Rhodes JF, Blaufox AD, Seiden HS, Asnes JD, Gross RP, Rhodes JP, et al. Cardiac arrest in infants after congenital heart surgery. Circulation. 1999;100: 194-9.

9. Eduardo BC, Javier SC, Francisco GV, Juan DJ, Felix PV, Luis AB, et al. Evaluation of the preoperative vasoactive-inotropic score as a predictor of postoperative outcomes in patients undergoing heart transplantation. Int J Cardiol. 2015;185:192-4.

10. Izabela K, Rafal S, Karolina B, Pawel T, Wojciech S. Validation of APACHE II and SAPS II scales at the intensive care unit along with assessment of SOFA scale at the admission as an isolated risk of death predictor. Anaesthesiol Intensive Ther. 2019;51(2):107-11.

11. Strumwasser A, Tobin JM, Henry R, Guidry C, Park C, Inaba K, et al. Extracorporeal membrane oxygenation in trauma: a single institution experience and review of the literature. Int J Artif Organs. 2018;41:845-53.

12. Recinos G, DuBose JJ, Teixeira PG, Barmparas G, Inaba K, Plurad D, et al. ACS trauma Centre designation and outcomes of post-traumatic ARDS: NTDB analysis and implications for trauma quality improvement. Injury. 2009;40: 856-9.

13. Cordell-Smith JA, Roberts N, Peek GJ, Firmin RK. Traumatic lung injury treated by extracorporeal membrane oxygenation (ECMO). Injury. 2006;37: 29-32.

14. Murphy DA, Hockings LE, Andrews RK, Aubron C, Gardiner EE, Pellegrino VA, et al. Extracorporeal membrane oxygenation-hemostatic complications. Transfus Med Rev. 2015;29:90-101.

15. Arlt M, Philipp A, Voelkel S, Rupprecht L, Mueller T, Hilker M, et al. Extracorporeal membrane oxygenation in severe trauma patients with bleeding shock. Resuscitation. 2010;81:804-9.

16. Muellenbach RM, Kredel M, Kunze E, Kranke P, Kuestermann J, Brack A, et al. Prolonged heparin-free extracorporeal membrane oxygenation in multiple injured acute respiratory distress syndrome patients with traumatic brain injury. J Trauma Acute Care Surg. 2012;72:1444-7.

17. Ried M, Bein T, Philipp A, Müller T, Graf B, Schmid C, et al. Extracorporeal lung support in trauma patients with severe chest injury and acute lung failure: a 10-year institutional experience. Crit Care. 2013;17:R110.

18. Schmid C, Philipp A, Hilker M, Rupprecht L, Arlt M, Keyser A, et al. Venovenous extracorporeal membrane oxygenation for acute lung failure in adults. J Heart Lung Transplant. 2012;31:9-15.

19. Enger T, Philipp A, Videm V, Lubnow M, Wahba A, Fischer M, et al. Prediction of mortality in adult patients with severe acute lung failure receiving veno-venous extracorporeal membrane oxygenation: a prospective observational study. Crit Care. 2014;18:R67.

20. Guirand DM, Okoye OT, Schmidt BS, Mansfield NJ, Aden JK, Martin RS, et al. Venovenous extracorporeal life support improves survival in adult trauma patients with acute hypoxemic respiratory failure: a multicenter retrospective cohort study. J Trauma Acute Care Surg. 2014;76:1275-81.

\section{Publisher's Note}

Springer Nature remains neutral with regard to jurisdictional claims in published maps and institutional affiliations.

\section{Ready to submit your research? Choose BMC and benefit from:}

- fast, convenient online submission

- thorough peer review by experienced researchers in your field

- rapid publication on acceptance

- support for research data, including large and complex data types

- gold Open Access which fosters wider collaboration and increased citations

- maximum visibility for your research: over $100 \mathrm{M}$ website views per year

At BMC, research is always in progress.

Learn more biomedcentral.com/submissions 